\title{
Detection of diarrheagenic Escherichia coli from children with and without diarrhea in Salvador, Bahia, Brazil
}

\author{
Vanessa Bueris, Marcelo Palma Sircili, Carla Romano Taddei, Maurilio Fernandes dos Santos, \\ Marcia Regina Franzolin/ ${ }^{+}$, Marina Baquerizo Martinez*, Suzana Ramos Ferrer**, \\ Mauricio Lima Barreto**, Luiz Rachid Trabulsi
}

\begin{abstract}
Laboratório de Bacteriologia, Instituto Butantan, Av. Vital Brazil 1500, 05503-900 São Paulo, SP, Brasil *Faculdade de Ciências Farmacêuticas, Departamento de Análises Clínicas e Toxicológicas, Universidade de São Paulo, São Paulo, SP, Brasil **Instituto de Saúde Coletiva, Universidade Federal da Bahia, Salvador, BA, Brasil
\end{abstract}

We identified different diarrheagenic (DEC) Escherichia coli pathotypes isolated from 1,207 children with and without acute endemic diarrhea in Salvador, Bahia, Brazil collected as part of a case-control study. Since the identification of DEC cannot be based on only biochemical and culture criteria, we used a multiplex polymerase chain reaction developed by combining five specific primer pairs for Enteropathogenic Escherichia coli (EPEC), Shiga toxin-producing E. coli/ Enterohaemorrhagic E. coli (STEC/EHEC), Enterotoxigenic E. coli (ETEC) and Enteroaggregative E. coli $(E A E C)$ to detect these pathotypes simultaneously in a single-step reaction. In order to distinguish typical and atypical EPEC strains, these were tested for the presence of EAF plasmid. The prevalence of diarrheagenic E. coli in this sample of a global case-control study was 25.4\% (259 patients) and $18.7 \%$ (35 patients) in the diarrhea group (1,020 patients) and the control group (187 patients), respectively. The most frequently isolated pathotype was EAEC (10.7\%), followed by atypical EPEC (9.4\%), ETEC (3.7\%), and STEC (0.6\%). Typical EPEC was detected only in one sample. The prevalence of the pathotypes studied in children with diarrhea was not significantly different from that in children without diarrhea.

Key words: diarrheagenic Escherichia coli - virulence - Multiplex PCR

Diarrhea continues to be one of the most common causes of morbidity and mortality among infants and children, especially in developing countries (WHO, 2002). The etiological agents of diarrhea include a wide range of viruses, bacteria and parasites. Among the bacterial pathogens, diarrheagenic Escherichia coli (DEC) is an important agent of endemic and epidemic diarrhea worldwide (Nataro \& Kaper 1998).

DEC strains can be classified into six main pathotypes on the basis of their specific virulence properties, association with some serotypes, and different epidemiological and clinical features.

Enteropathogenic E. coli (EPEC) cause a histopathological lesion known as "attaching and effacing" (A/E). Strains of the A/E genotype, which do not possess the Enteropathogenic E. coli adherence factor (EAF) plasmid, are classified as atypical EPEC (a-EPEC) (Trabulsi et al. 2002). The term Shiga toxin-producing E. coli (STEC) is now used to define any E. coli strain that produces Stx, and enterohemorrhagic E. coli (EHEC) is used to denote the Stx-positive strains that also contain locus of enterocyte effacement (LEE) (Kaper et al. 2004).

Financial support: Pronex (Contract 661086/1998-4) ${ }^{+}$Corresponding author: mrfranzolin@butantan.gov.br This work is dedicated to Luiz Rachid Trabulsi (in memoriam) who supervised this study and inspired us to continue his work. Received 21 May 2007

Accepted 5 October 2007
Enterotoxigenic E. coli (ETEC) are associated with watery diarrhea among children in developing countries and are the main cause of traveler's diarrhea in adults visiting endemic areas. Enteroaggregative E. coli (EAEC) are defined as $E$. coli strains that adhere in vitro to HEp-2 cells in a pattern known as autoaggregative. Enteroinvasive $E$. coli (EIEC) are capable of invading the colonic epithelium and spreading from cell to cell, which may occasionally cause dysentery. Diffusely adherent $E$. coli (DAEC) are defined by a characteristic diffuse pattern of adherence to HEp-2 cells (Nataro \& Kaper 1998).

The identification of DEC cannot be based only on cultural and biochemical criteria, since they are indistinguishable from the non-pathogenic E. coli commonly found in human feces. Moreover, specific serotyping is not always correlated with pathogenicity. Since several virulence factors and DNA sequences of DEC have been identified, they can be determined by the presence of genes coding for specific virulence factors, which are absent in non-pathogenic strains. Polymerase chain reaction (PCR) is a commonly used method that gives rapid, reliable results, and shows high sensitivity and high specificity. Several PCR methods, with both single and multiple target genes, have been reported for detecting the different DEC pathotypes. In order to simplify the identification, we developed a multiplex PCR combining five specific primer pairs for EPEC, STEC, ETEC, and EAEC virulence genes, to detect these pathotypes simultaneously in a single-step reaction. Since the incidence of EIEC is very low and DAEC is not well defined as a distinct pathotype, their detection was not included in this study. 


\section{MATERIALS AND METHODS}

Study population - From February, 2003 to September, 2004, stool samples from 1,207 children (1 to 10 years of age) were collected as part of a case control study, with the aim of identifying risk factors for diarrhea, involving 3,234 children ( $<10$ years of age) in the city of Salvador, which included 1,688 cases and 1,676 controls. Cases and controls were selected from patients of five outpatient clinics from various areas of Salvador, state of Bahia, Brazil. Cases were defined as children whose main complaint was acute diarrhea, characterized by the occurrence of three or more, loose, liquid, or watery stools in a $24 \mathrm{~h}$ period. Controls were children being seen at the same clinics for reasons other than diarrhea, without any gastrointestinal symptoms for at least 21 days before inclusion in the study. Clinical and epidemiological information were obtained through questionnaires. The global case-control study sample consisted of 1,688 diarrhea cases and 390 controls $(23 \%$ of the total 1,676 controls), and the present study included 1,020 diarrheic and 187 control children, representing a partial analysis of the case-control study.

Pathogen identification - Stool samples collected in Cary-Blair transport medium were cultured on different solid media. MacConkey agar (Merck) was used to select $E$. coli isolates. As a rule 2-3 lactose-fermenting colonies, presumed to be E. coli by colony morphology, were selected and submitted to biochemical tests. E. coli isolates were stored at $-80^{\circ} \mathrm{C}$ in trypticase soy broth (TSB) supplemented with $20 \%$ glycerol for further procedures. Bacterial testing for Salmonella, Shigella, Yersinia, Aeromonas, and Campylobacter jejuni-coli was conducted using standard procedures (Steele \& McDermott 1984, Koneman et al. 1997). Adenovirus, Astrovirus, and Rotavirus (group A) were identified by enzyme immunoassay (Biomanguinhos, Oswaldo Cruz Foundation) and polyacrylamide gel electrophoresis
(PAGE). Parasitological examinations for helminthes and protozoa were conducted using the Kato-Katz (Katz et al. 1972) and sedimentation (Koneman et al. 1997) methods. To test for Cryptosporidia sp, stool specimens were sieved and submitted to the formol-ether concentration method (Allen \& Ridley 1970).

Multiplex PCR - DNA templates for PCR were obtained from overnight $E$. coli cultures that were pelleted, resuspended in $500 \mu \mathrm{l}$ of sterile deionized water and boiled for $10 \mathrm{~min}$. The multiplex PCR was developed by combining five specific primer pairs for EPEC, STEC/ EHEC, ETEC, and EAEC virulence genes, as described in Table I. Each multiplex reaction was performed in a 50 $\mu \mathrm{l}$ final volume containing $1 \mu \mathrm{l}$ of the template DNA, 0.2 mM DNTPs, 10 mM Tris- $\mathrm{HCl}$ (pH8.8), $1.5 \mathrm{mM} \mathrm{MgCl}_{2}, 50$ $\mathrm{mM} \mathrm{KCl}, 2 \mathrm{U}$ Taq DNA polymerase (Invitrogen), and 10 pmol of each primer (Biosynthesis). The thermocycling conditions were as follows: $94^{\circ} \mathrm{C}$ for $5 \mathrm{~min}, 94^{\circ} \mathrm{C}$ for $45 \mathrm{~s}$, $50^{\circ} \mathrm{C}$ for $1 \mathrm{~min}$, and $2 \mathrm{~min}$ and $72^{\circ} \mathrm{C}$ for 35 cycles, with a final 9 min extension at $72^{\circ} \mathrm{C}$. Amplified samples were evaluated by $1 \%$ agarose gel electrophoresis in Tris-borate-EDTA buffer and ethidium bromide staining.

$D E C$ detection - DNA templates from the stored $E$. coli isolates were submitted to multiplex PCR as described above. The eae-positive strains were tested by PCR for the presence of EAF plasmid, as described by Franke et al. (1994). In all experiments, the prototype EPEC E2348/69, EAEC 042, ETEC H10407 (LT), ETEC C275/15 (ST), and EHEC O157:H7 strains were used as positive control, while $E$. coli $\mathrm{K} 12 \mathrm{DH} 5 \alpha$ was the negative control.

Serotyping - The somatic $(\mathrm{O})$ and flagellar $(\mathrm{H})$ antigens of STEC (eae positive) strains and typical EPEC were determined by standard agglutination methods using O1 to O172 and H1 to H51 (Orskov \& Orskov 1984).

TABLE I

Sequence of polymerase chain reaction (PCR) primers, sizes of amplified DNA fragments and concentration of multiplex PCR

\begin{tabular}{|c|c|c|c|c|}
\hline Gene & Sequence (5'- 3') & $\begin{array}{l}\text { Product } \\
\text { size (bp) }\end{array}$ & {$[\mathrm{pmol}]$} & Reference \\
\hline $\begin{array}{l}\text { eae } \\
\text { (EPEC) }\end{array}$ & $\begin{array}{l}\text { IntFC - CCGGAATTCGGGATCGATTACCGTCAT } \\
\text { IntRC - CCAAGCTTTTATTTATCAGCCTTAATCTC }\end{array}$ & 820 & 100 & Batchelor et al. (1999) \\
\hline $\begin{array}{l}\text { LT } \\
(\text { ETEC) }\end{array}$ & $\begin{array}{l}\text { LTFW - GGCGACAGATTATACCGTGC } \\
\text { LTREV - CCGAATTCTGTTATATATGTC }\end{array}$ & 696 & 20 & Schultsz et al. (1994) \\
\hline $\begin{array}{l}\text { ST } \\
(\text { ETEC) }\end{array}$ & $\begin{array}{l}\text { STFW - TCCCTCAGGATGCTAAAC } \\
\text { STREV - GCAACAGGTACATACGTT }\end{array}$ & 240 & 20 & Moseley et al. (1983) \\
\hline $\begin{array}{l}\text { Stx } \\
(\text { STEC) }\end{array}$ & $\begin{array}{l}\text { StxUFW - GAACGAAATAATTTATATGT } \\
\text { StxUREV - TTTGATTGTTACAGTCAT }\end{array}$ & 500 & 75 & Yamasaki et al. (1996) \\
\hline $\begin{array}{l}\text { AA } \\
\text { (EAEC) }\end{array}$ & $\begin{array}{l}\text { pCVD432FW - CTGGCGAAAGACTGTATCAT } \\
\text { pCVD432REV_CAATGTATAGAAATCCGCTGTT }\end{array}$ & 630 & 20 & Schmidt et al. (1995) \\
\hline
\end{tabular}

EPEC: Enteropathogenic E. coli; ETEC: Enterotoxigenic E. coli; STEC: Shiga toxin-producing E. coli; EAEC: Enteroaggregative E. coli. 
Statistical assessment was performed using Pearson's chi-square test, where values $<0.05$ were considered statistically significant.

\section{RESULTS}

A total of 1,020 children with diarrhea and 187 control children without diarrhea were studied. Diarrheagenic E. coli was isolated from $25.4 \%$ of the children with diarrhea (259 patients) compared with $18.7 \%$ of children without diarrhea (35 patients). The frequency of each DEC pathotype is shown in Table II. The most frequently isolated was EAEC (10.7\%), followed by atypical EPEC (9.4\%), ETEC (3.7\%), and STEC $(0.6 \%)$. Typical EPEC was detected only in one sample $(0.1 \%)$, and it belonged to serotype O142:H34. Thirty- two ETEC strains were positive for the LT gene and five for the ST gene, while seven strains possessed both genes. Only four patients displayed two pathotypes simultaneously (a-EPEC and EAEC - 3 patients; EAEC and ETEC - 1 patient). E. coli strains containing the target genes were not identified in the stools from the other 152 (81.3\%) patients without diarrhea and $761(74.6 \%)$ patients with diarrhea. The three STEC strains that had eae gene identified by PCR belonged to serotypes O157:H7, $\mathrm{O} 26: \mathrm{H} 11$ (control patients), and $\mathrm{O} 111: \mathrm{H}^{-}$(case patient). DEC was isolated in the stools as the sole enteric pathogen agent in $199(67.7 \%)$ of 294 patients, and in the remaining 95 (32.3\%) children, DEC was associated with some other pathogens (Table III).

TABLE II

Frequency of Escherichia coli pathotypes in children with and without diarrhea

\begin{tabular}{lcccc}
\hline E. coli pathotype & Control patients $(\mathrm{n}=187)(\%)$ & Case patients $(\mathrm{n}=1020)(\%)$ & $p^{a}$ & Total $(\mathrm{n}=1207)(\%)$ \\
\hline EAEC & $16(8.6)$ & $113(11.1)^{b}$ & 0.30 & $129(10.7)$ \\
a-EPEC & $c$ & $102(10.0)$ & 0.07 & $113(9.4)$ \\
ETEC & $11(5.9)$ & $38(3.7)^{d}$ & 0.73 & $44(3.7)^{i}$ \\
STEC & $6(3.2)^{g}$ & $5(0.5)^{f}$ & $7(0.6)$ & $1(0.1)$ \\
t-EPEC & $2(1.1)^{e}$ & $1(0.1)$ & 0.05 & $294(24.4)$ \\
\hline Total & 0 & $259(25.4)$ & $35(18.7)$ &
\end{tabular}

$a$ : chi-square test; $b$ : three patients had Enteroaggregative $E$. coli (EAEC) strain and atypical Enteropathogenic $E$. coli (a-EPEC) strain; $c$ : three strains had the LT gene; $d$ : one patient had Enterotoxigenic E. coli (ETEC) strain (LT +) and Enteroaggregative E. coli (EAEC) strain; $e$ : two strains had the eae gene, and belonged to serotypes O26:H11, and O157:H7; $f$ one strain had the eae gene (O111: $\mathrm{H}^{-}$serotype); $g$ : LT gene - five strains; ST and LT genes - one strain; $h$ : LT gene - 27 strains; ST and LT genes - six strains; ST gene - five strains; $i$ : LT gene - 32 strains; ST gene - five strains; ST and LT - seven strains.

TABLE III

Pathogenic species identified in the fecal samples positive for diarrheagenic Escherichia coli

\begin{tabular}{|c|c|c|}
\hline Type & No. of cases & Other pathogens identified ${ }^{a}$ (no. of patients) \\
\hline t-EPEC & 1 & Rotavirus (1) \\
\hline EAEC & 129 & $\begin{array}{l}\text { Ascaris lumbricoides, Trichuris trichiura, and Entamoeba } \\
\text { coli }\left(1^{b}\right), \text { E. histolytica, E. coli and Cryptosporidium parvum } \\
\text { (1), C. parvum (3), Astrovirus (1), Adenovirus (3), } \\
\text { Ancylostoma duodenale (1), T. trichiura and Rotavirus } \\
\text { (1), Giardia lambia (1), Rotavirus }\left(32^{b}\right)\end{array}$ \\
\hline a-EPEC & 113 & $\begin{array}{l}\text { A. lumbricoides (1), E. histolytica, E. coli and G. lambia } \\
\text { (1), A. lumbricoides and T. trichiura }(2), \text { T. trichiura }\left(2^{b}\right) \text {, } \\
\text { T. trichiura and Rotavirus (1), C. parvum (1), E. histolytica and } \\
\text { E. coli (1), Rotavirus (28) }\end{array}$ \\
\hline ETEC & 44 & $\begin{array}{l}\text { A. lumbricoides (2), A. lumbricoides and Rotavirus (1), } \\
\text { A. lumbricoides and T. trichiura (1), Adenovirus (1), } \\
\text { Campylobacter jejuni-coli (1), Rotavirus (6) }\end{array}$ \\
\hline STEC & 7 & Rotavirus (1) \\
\hline Total & 294 & $95(32.3 \%)$ \\
\hline
\end{tabular}

$a$ : other enteropathogenic bacteria were not isolated in the clinical samples; $b$ : one sample of control patient; t-EPEC: typical Enteropathogenic E. coli; EAEC: Enteroaggregative E. coli; a-EPEC: atypical Enteropathogenic E. coli; ETEC: Enterotoxigenic E. coli; STEC: Shiga toxin-producing E. coli. 


\section{DISCUSSION}

Phenotypic assays are routinely used in most laboratories to characterize DEC strains. However, these methods alone are not sufficient to identify all five pathotypes of DEC (Brandal et al. 2007). The genes encoding virulence factors are extensively studied and characterized, and several PCR methods have been developed to identify the virulence genes of DEC (Kimata et al. 2005). Numerous multiplex PCR assays have been developed to identify DEC, and assays were recently described that are capable of distinguishing the five pathotypes of DEC (Aranda et al. 2004, Nguyen et al. 2005).

In this study, five distinct pathotypes and subpathotypes of diarrheagenic $E$. coli were detected in children with and without acute diarrhea in Salvador, Bahia. We were able to save time and effort involved in testing for various virulence factors, reducing the number of gene detection assays by developing a multiplex PCR method that has been shown to be highly sensitive and specific, using primers for the different DEC pathotypes in a single reaction.

EAEC was the most commonly isolated pathotype, followed by atypical EPEC, whereas the frequency of tEPEC was very low. In addition, we identified seven STEC strains, and three of these strains harbored the eae gene, but two of them were from control patients. Interestingly, the only one O157:H7 STEC strain identified in this study was isolated from a child without diarrhea. The prevalence of the pathotypes studied in children with diarrhea was not significantly different from children without diarrhea.

ETEC and EAEC have been frequently detected in children with diarrhea in studies conducted in Brazil and in other countries (Gomes et al. 1991, 1996, Nataro \& Kaper 1998, Scaletsky et al. 2002, Zamboni et al. 2004, Regua-Mangia et al. 2004), which is in agreement with the results reported in this study. EAEC is emerging as an enteric pathogen of great concern, responsible for acute and persistent diarrhea ( $\geq 14$ days) and may cause malnutrition and growth defects in children. These strains have been associated with traveler's diarrhea in both developing and industrialized countries, and have been isolated in immunocompromised patients (Nataro 2005).

Previous studies were conducted in Salvador, Bahia to determine the presence of DEC in acute endemic diarrhea. Tornieporth et al. (1995) analyzed stool samples from children with and without diarrhea by PCR. They only investigated virulence marker genes of ETEC, EPEC, and EIEC, identifying $16 \%, 8 \%$, and $1 \%$ of the children with these pathotypes, respectively. Another epidemiological study conducted by our group examined children with acute endemic diarrhea in Salvador, by colony blot hybridization including other virulence factors (Franzolin et al. 2005, Barreto et al. 2006). The most frequently isolated was atypical EPEC $(10.1 \%)$ followed by ETEC (7.5\%), and EAEC (4.2\%). STEC eae-positive (serotype O26:H11), STEC and typical EPEC were each detected once.

In the present study we analyzed a greater number of patients and also included controls. The isolation of only one typical EPEC strain confirms a recent trend that has been observed in São Paulo and in other Brazilian states (Gomes et al. 2004, Franzolin et al. 2005), showing a drastic decline in the frequency of typical EPEC with the frequency of atypical EPEC strains on the rise. Up to the 1990s, typical EPEC was the main cause of acute diarrhea in children younger than one year old, of low socio-economic status, in Brazil (Gomes et al. 1991, Trabulsi et al. 2002, Regua-Mangia et al. 2004), but such is currently very rare. This situation also occurred in developed countries, where up to the 1960s typical EPEC was frequently isolated as the cause of outbreaks and sporadic cases of diarrhea, but is currently very rare, while the frequency of atypical EPEC strains has increased (Afset et al. 2003). Outbreaks of adult gastroenteritis due to atypical EPEC have been reported (Viljanen et al. 1990, Hedberg et al. 1997). t-EPEC have not been isolated from animals (Nataro \& Kaper 1998), and thus humans appear to be the unique living reservoir for these organisms. It is likely that the frequency of tEPEC has been influenced by the recently improved public health measures, such as more efficient control of hospital infections and implementation of sanitary conditions, more so than the frequency of a-EPEC and EHEC which are hosted by humans and animals (Trabulsi et al. 2002).

This is the second time that STEC/EHEC strains were isolated in Salvador, but to our knowledge, the O157:H7 serotype has been isolated in this city only in the present study. However, O157:H7 and O26:H11 serotypes were isolated from children belonging to the control group. No blood was reported in the feces of the children with STEC/EHEC. In Brazil, infections due to STEC have been identified in sporadic cases of non-bloody diarrhea, particularly in young children (Gomes et al. 1996, Cantarelli et al. 2000, Guth et al. 2002, 2005, Bastos et al. 2006). Irino et al. (2002) isolated three O157:H7 strains from bloody diarrhea, and one HUS case due to an O26:H11 strain has been recently described in São Paulo, Brazil (Guth et al. 2002). Among non-O157 STEC, serotypes O111:NM, O111:H8, and O26:H11 have been identified as agents of infantile diarrhea in São Paulo, since the late 1970s (Vaz et al. 2004). STEC/EHEC are frequently detected in food and in animal reservoirs in Brazil (Cerqueira et al. 1999, Leomil et al. 2003, Bastos et al. 2006), but only some of the serotypes identified in animals have been recognized as causes of human illness. Bastos et al. (2006) studied eighteen strains of the O157:H7 serotype isolated from animals and from bloody diarrhea and HUS in humans during different surveys conducted in Brazil, suggesting that this serotype is emerging in this country. These findings point to the need for more effective measures from our public health services.

Tests for the presence of other pathogens were according to standard methods: Ascaris lumbricoides, Ancylostoma duodenale, Trichuris trichiura, Entamoeba coli, E. histolytica, Giardia lambia, Cryptosporidium parvum, C. jejuni-coli, Astrovirus, Adenovirus, and Rotavirus. No other bacterial pathogens were isolated in the patients infected with DEC, but 32.5\% (95 patients) of them also carried parasites or viruses, mainly Rotavirus, which is associated with severe acute, watery diarrhea. 
As the virulence determinants of atypical EPEC are relatively unknown, further studies are needed to investigate the ecological, socio-economic and epidemiological basis of this emerging pathotype.

\section{REFERENCES}

Afset JE, Bergh K, Bevanger L 2003. High prevalence of atypical enteropathogenic Escherichia coli (EPEC) in Norwegian children with diarrhoea. JMed Microbiol 52: 1015-1019.

Allen AVD, Ridley DS 1970. Further observations on the formolether concentration technique for fecal parasites. $J$ Clin Pathol 23: 545.

Aranda KR, Fagundes-Neto U, Scaletsky IC 2004. Evaluation of multiplex PCRs for diagnosis of infection with diarrheagenic of Escherichia coli and Shigella spp. J Clin Microbiol 42: 5849-5853.

Barreto ML, Milroy CA, Strina A, Prado MS, Leite JP, Ramos EA, Ribeiro H, Alcantara-Neves NM, Teixeira MD, Rodrigues LC, Ruf H, Guerreiro H, Trabulsi LR 2006. Community-based monitoring of diarrhea in urban Brazilian children: incidence and associated pathogens. Trans $R$ Soc Trop Med Hyg 100: 234-242.

Bastos FC, Vaz TM, Irino K, Guth BE 2006. Phenotypic characteristics, virulence profile and genetic relatedness of O157 Shiga toxin-producing Escherichia coli isolated in Brazil and other Latin American countries. FEMS Microbiol Lett 265: 89-97.

Batchelor M, Knutton S, Caprioli A, Huter V, Zanial M, Dougan G, Frankel G 1999. Development of a universal intimin antiserum and PCR primers. J Clin Microbiol 37: 3822-387.

Brandal LT, Lindstetd BA, Lena A, Stavnes TL, Lassen J, Kapperud G 2007. Octaplex PCR and fluorescence-based capillary electrophoresis for identification of human diarrheagenic Escherichia coli and Shigella ssp. JMicrobiol Methods 68: 331-342.

Cantarelli V, Nagayama K, Takahashi A, Honda T, Cauduro PF, Dias GAG, Mezzari A, Brodt T 2000. Isolation of Shiga toxinproducing Escherichia coli (STEC) serotype O91:H21 from a child with diarrhea in Porto Alegre city, RS, Brazil. Braz J Microbiol 31: 266-270.

Cerqueira AMF, Guth BEC, Joaquim RM, Andrade JRC 1999. High occurrence of Shiga toxin-producing Escherichia coli (STEC) in healthy cattle at Rio de Janeiro State, Brazil. Vet Microbiol 70: 111-121.

Franke J, Franke S, Schmidt H, Schwarzkopf A, Wieler LH, Baljer G, Beutin L, Karch H 1994. Nucleotide sequence analysis of enteropathogenic Escherichia coli (EPEC) adherence factor probe and development of PCR for rapid detection of EPEC harboring virulence plasmids. J Clin Microbiol 32: 2460-2463.

Franzolin MR, Alves RCB, Keller R, Gomes TAT, Beutin L, Barreto ML, Milroy CA, Strina A, Ribeiro H, Trabulsi LR 2005. Prevalence of diarrheagenic Escherichia coli in children with diarrhea in Salvador, Bahia, Brazil. Mem do Instituto Oswaldo Cruz 100: 359-363.

Gomes TAT, Griffin PM, Ivey C, Trabulsi LR, Ramos SRTS 1996. EPEC infections in São Paulo. Rev Microbiol 27: 25-33.

Gomes TAT, Irino K, Girão DM, Girão VB, Guth BE, Vaz TM, Moreira FC, Chinarelli SH, Vieira MA 2004. Emerging enteropathogenic Escherichia coli strains? Emerg Infect Dis 10: 1851-185.
Gomes TAT, Rassi V, MacDonald KL, Ramos SR, Trabulsi LR, Vieira MA 1991. Enteropathogens associated with acute diarrheal disease in urban infants in São Paulo, Brazil. J Infect Dis 164: 331-337.

Guth BEC, Lopes R, Vaz TMI, Irino K 2002. First Shiga toxinproducing Escherichia coli isolate from a patient with hemolytic uremic syndrome in Brazil. Emerg Infect Dis 8: 535-536.

Guth BEC, Vaz TM, TA Gomes TA, Chinarelli SH, Rocha MM, de Castro AF, Irino K 2005. Re-emergence of O103:H2 Shiga toxin-producing Escherichia coli infections in São Paulo, Brazil. J Med Microbiol 54: 805-806.

Hedberg C, Savarino S, Besser J, Paulus C, Thelen V, Myers L, Cameron DN, Barrett TJ, Kaper JB, Osterholm MT 1997. An outbreak of foodborne illness caused by Escherichia coli O39:NM, an agent not fitting into the existing scheme for classifying diarrheogenic E. coli. J Infect Dis 176: 1625-1628.

Irino K, Vaz TMI, Kato MAMF, Naves ZVF, Lara RR, Marco MEC, Rocha MM, Moreira TP, Gomes TA, Guth BE 2002. O157:H7 Shiga toxin-producing Escherichia coli strains associated with sporadic cases of diarrhea in São Paulo, Brazil. Emerg Infect Dis 8: 446-447.

Kaper JB, Nataro JP, Mobley HLT 2004. Pathogenic Escherichia coli. Nat Rev Microbiol 2: 123-40.

Katz N, Chaves A, Pellegrino J 1972. A simple device for quantitative stool thick-smear technique in schistosomiasis mansoni. Rev Inst Med Trop São Paulo 14: 397-400.

Kimata K, Shima T, Shimizu M, Tanaka D, Isobe J, Gyobu Y, Watahiki M, Nagai Y 2005. Rapid Categorization of Pathogenic Escherichia coli by Multiplex PCR. Microbiol Immunol 49: 485-492

Koneman EW, Allen SD, Janda WM, Schreckenberger PC, Winn Jr WC 1997. Diagnostic Microbiology. Color Atlas and Textbook, 5th ed., Lippincott. Philadelphia, Pennsylvania, $1395 \mathrm{pp}$.

Leomil L, Akdar-Ugrinovich L, Guth BE, Irino K, Vettorato MP, Onuma DL, de Castro AF 2003. Frequency of Shiga toxinproducing Escherichia coli (STEC) isolates among diarrheic and non-diarrheic calves in Brazil. Vet Microbiol 97: 103-109.

Moseley SL, Hardy JW, Hug MI, Echeverria P, Falkow S 1983. Isolation and nucleotide sequence determination of a gene encoding a heat-stable enterotoxin of Escherichia coli. Infect Immun 39: 1167-1174.

Nataro JP 2005. Enteroaggregative Escherichia coli pathogenesis. Curr Opin Gastroenterol 21: 4-8.

Nataro JP, Kaper JB 1998. Diarrheagenic Escherichia coli. Clin Microbiol Rev 11: 142-201.

Nguyen TV, Le Van P, Le Huy C, Gia KN, Weintraub A 2005. Detection and characterization of diarrheagenic Escherichia coli from young children in Hanoi, Vietnam. JClin Microbiol 43: 755-760.

Orskov F, Orskov I 1984. Serotyping of Escherichia coli. Methods Microbiol 14: 43-112.

Regua-Mangia AH, Gomes TAT, Vieira MAM, Andrade JRC, Irino K, Teixeira LM 2004. Frequency and characteristics of diarrhoeagenic Escherichia coli strains isolated from children with and without diarrhoea in Rio de Janeiro, Brazil. $J$ Infect 48: 161-167. 
Scaletsky IC, Fabbricotti SH, Silva SO, Morais MB, FagundesNeto U 2002. HEp-2-adherent Escherichia coli strains associated with acute infantile diarrhea, São Paulo, Brazil. Emerg Infect Dis 8: 855-858.

Schimidt H, Knop C, Franke S, Aleksic S, Heesemann J, Karch H 1995. Development of PCR for screening of enteroaggregative Escherichia coli. J Clin Microbiol 33: 701-705.

Schultsz C, Pool GJ, van Ketel R, de Wever B, Speelman P, Dankert J 1994. Detection of enterotoxigenic Escherichia coli in stool samples by using nonradioactively labeled oligonucleotide DNA probes and PCR. J Clin Microbiol 32: 2393-2397.

Steele TW, McDermott SN 1984. The use of membrane filters applied directly to the surface of agar plates for the isolation of Campylobacter jejuni from feces. Pathol 16: 263-265.

Tornieporth NG, John J, Salgado K, de Jesus P, Latham E, Melo MC, Gunzburg ST, Riley LW 1995. Differentiation of pathogenic Escherichia coli strains in Brazilian children by PCR. J Clin Microbiol 33: 1371-1374.

Trabulsi LR, Keller R, Gomes TAT 2002. Typical and atypical enteropathogenic Escherichia coli. Emerg Infect Dis 8: 508-513.
Vaz TM, Irino K, Kato MA, Dias AM, Gomes TA, Medeiros MI, Rocha MM, Guth BE 2004. Virulence properties and characteristics of Shiga toxin-producing Escherichia coli in São Paulo, Brazil, from 1976 through 1999. J Clin Microbiol 42: 903-905.

Viljanen M, Peltola T, Junnila S, Olkkonen L, Jarvinen H, Kuistila M, Huovinen P 1990. Outbreak of diarrhoea due to Escherichia coli O111:B4 in school children and adults: association of Vi antigen-like reactivity. Lancet 336: 381-384.

WHO - World Health Organization 2002. Reducing Risks, Promoting Healthy Life. The World Health Report (http:// www.who.int/whr/en/).

Yamasaki S, Lin Z, Shirai H, Terai A, Oku Y, Ito H, Ohmura M, Karasawa T, Tsukamoto T, Kurazono H, Takeda Y 1996. Typing of verotoxins by DNA colony hybridization with polyand oligonucleotide probes, a bead-enzyme-linked immunosorbent assay, and polymerase chain reaction. Microbiol Immunol 40: 345-52.

Zamboni A, Fabbricotti SH, Fagundes-Neto U, Scaletsky IC 2004. Enteroaggregative Escherichia coli virulence factors are found to be associated with infantile diarrhea in Brazil. JClin Microbiol 42: 1058-63. 